\title{
Informatics-Lab: Attracting Primary School Pupils for Computer Science
}

\author{
Stefan Pasterk, $\mathrm{Msc}^{1}$, Barbara Sabitzer, $\mathrm{PhD}^{1}$, Heike Demarle-Meusel, $\mathrm{PhD}^{1}$, and Andreas Bollin, $\mathrm{PhD}^{1}$ \\ University of Klagenfurt, Austria, stefan.pasterk@aau.at, barbara.sabitzer@aau.at, heike.demarle-meusel@aau.at, \\ andreas.bollin@aau.at
}

\begin{abstract}
Technology has a deep impact on everyday life of most people in today's society. Informatics is a basic element of this evolution and is. therefore getting more and more important for education, too. To introduce children of all ages to different topics of informatics, the Regional Educational Competence Centre for Informatics in Carinthia, Austria, organized a four-week lasting Informatics-Lab. During their holidays in July 2014, children were able to visit our university, participate in workshops and get a first or a deeper impression of topics like encryption, operating systems, networks or modelling. What distinguished this project from other labs was that the children learned from trainees aged between 16 and 19 years as well as from their peers. Furthermore, trainees and visitors developed new teaching material on their own. This was an important element of the project as it considered different learning concepts like learning by teaching. The lab got positive feedback from both, children and parents. A pre-post comparison showed that the project had positive effects on the interest as well as on the attitude towards informatics. This paper gives some background information about the learning concept and an overview of the activities and stations. Furthermore, the results from an empirical survey are presented.

Keywords-- Learning lab; informatics; primary education
\end{abstract}

Digital Object Identifier

(DOI):http://dx.doi.org/10.18687/LACCEI2016.1.1.242

ISBN: 978-0-9822896-9-3

ISSN: 2414-6390

$14^{\text {th }}$ LACCEI International Multi-Conference for Engineering, Education, and Technology: "Engineering Innovations for Global Sustainability", 20-22 July 2016, San José, Costa Rica. 


\title{
Informatics-Lab: Attracting Primary School Pupils for Computer Science
}

\author{
Stefan Pasterk, $\mathrm{Msc}^{1}$, Barbara Sabitzer, $\mathrm{PhD}^{1}$, Heike Demarle-Meusel, $\mathrm{PhD}^{1}$, and Andreas Bollin, $\mathrm{PhD}^{1}$ \\ ${ }^{1}$ University of Klagenfurt, Austria, stefan.pasterk@aau.at, barbara.sabitzer@aau.at, heike.demarle-meusel@aau.at, \\ andreas.bollin@aau.at
}

\begin{abstract}
Technology has a deep impact on everyday life of most people in today's society. Informatics is a basic element of this evolution and is. therefore getting more and more important for education, too. To introduce children of all ages to different topics of informatics, the Regional Educational Competence Centre for Informatics in Carinthia, Austria, organized a four-week lasting Informatics-Lab. During their holidays in July 2014, children were able to visit our university, participate in workshops and get a first or a deeper impression of topics like encryption, operating systems, networks or modelling. What distinguished this project from other labs was that the children learned from trainees aged between 16 and 19 years as well as from their peers. Furthermore, trainees and visitors developed new teaching material on their own. This was an important element of the project as it considered different learning concepts like learning by teaching. The lab got positive feedback from both, children and parents. A pre-post comparison showed that the project had positive effects on the interest as well as on the attitude towards informatics. This paper gives some background information about the learning concept and an overview of the activities and stations. Furthermore, the results from an empirical survey are presented.

Keywords-- Learning lab; informatics; primary education
\end{abstract}

\section{INTRODUCTION}

Informatics is a science that has a deep impact upon everyone's daily life and in today's society it can be found everywhere. The role of informatics in education is also growing. Different schools and school-types often provide the subject "Informatics" teaching digital literacy or programming. But informatics is much more than that. Related to Computational Thinking, which captures "the distinctive contribution of informatics as a paradigm for looking at the world" [1], it includes skills like problem solving or designing systems. Wing [2] further describes computational thinking as "a fundamental skill for everyone". Therefore, the main concepts of informatics should be included in general education.

In Austrian schools, informatics education is not organized uniformly. With the exception of some schools with a special IT-orientation, informatics only starts in the $9^{\text {th }}$ grade, at the age of 14. This may be late for arousing interest in technology. With different projects, the Regional Educational Competence Centre (RECC) for Informatics in Carinthia, Austria, wants to give children the possibility to get in touch with technology and informatics concepts as an additional offer to school education. The RECC is a cooperation between the regional stakeholders in education: the Department of Informatics Didactics of the Alpen-Adria-

Digital Object Identifier (DOI): http://dx.doi.org/10.18687/LACCEI2016.1.1.242 ISBN: 978-0-9822896-9-3

ISSN: $2414-6390$
University Klagenfurt, the University College of Teacher Education in Carinthia, the Carinthian Educational Board (Landesschulrat) and the Division of Education in the regional government. As part of the running project "Informatics - A child's play" [3] these institutes organized an open Informatics-lab called "Informatikwerkstatt zum Mitmachen" (Informatics-Lab to join in). During four weeks in July 2014, interested children, parents and teachers were invited to visit the Lab to get a first impression of university and informatics. The main aims of this endeavor can be summarized as follows:

- Increase the interest in informatics, engineering and technology as early as possible.

- Consolidate student and teacher knowledge about informatics (concepts, usage, career, etc.).

- Foster general learning skills like text comprehension, problem solving, logical thinking or creativity.

- Develop and evaluate brain-friendly teaching material.

A playful, fun and "cool" approach to technology and informatics that is implemented during early childhood could do more than raising the interest and laying a good foundation for logical and computational thinking. It may also mitigate fears or gender differences regarding interests and performance in technical subjects. An interdisciplinary and cross-curricular use of computer science concepts (NOT only computers) does not only offer more possibilities of practice for more sustainable learning. Besides showing a wide range of application areas of computer science, it can also foster creativity as well as cross-linked thinking and it can support teaching and learning in other subjects. Especially the lab focused on the three target groups:

- Participating children of all ages: the children could visit the lab, get some information in short workshops and apply learned concepts to exercises or work out their own materials.

- Trainees aged between 16 and 19 years: seven students from different schools and ages attended a one-month lasting internship at the Department of Informatics Didactics with the tasks to become acquainted to the topics and concepts of informatics, to guide the visitors through the stations, explain the informatics concepts and to work out new teaching materials considering their previous knowledge and interests. 
- Interested teachers: teachers from all school types could visit the lab to inform themselves about different topics and to get new ideas of teaching informatics concepts in class. They could participate in the workshops or work on new units for school.

All of them had the possibility to learn new content and to consolidate it by teaching other participants. The next section describes the pedagogical background of the project. After these basics, we present the stations and some sample activities of the Informatics-Lab. The last section contains the evaluation including the methods used and some empirical results. Additionally, some outcomes from the participants are shown.

\section{THE CONCEPT: COOL INFORMATICS}

Sabitzer [4] developed the teaching approach "COOL Informatics", which is based on neurodidactical principles. First of all, it should be defined what the acronym COOL means in the context of "COOL Informatics". The following meanings are considered in this approach and it is obvious that they come from different research fields:

1. "Cool" means motivating, interesting, fun and effective.

2. COoperative Open Learning is an Austrian teaching model [5] that offers thematic, methodic and institutional openness as well as cooperation on different levels and between different subjects.

3. COmputer-supported Open Learning refers to all forms of technology-supported learning, like CSCL (Computer-supported Collaborative Learning), E-Learning or Mobile Learning as well as eCOOL, the ELearning variant of the COOL teaching model.

"COOL Informatics" is not simply combining all these fields to one approach, but it goes one step further. On the one hand it extends the aspect of computer-supported learning to "computer science-supported" by implementing core concepts of informatics in other subjects wherever possible and reasonable (e.g. by comparing algorithms and the description of the way to school). On the other hand, it gets a new framework and bases on neurodidactical principles. Corresponding to the different meanings, the theoretical background of the "COOL Informatics" approach includes numerous teaching concepts and methods as well as a wide range of related work. It would go beyond the scope of this paper to consider all these fields in depth. As a result, only the most relevant literature is cited in the context of each realm. An overview of the four principles of this approach discovery, cooperation, individuality and activity, can be seen in Table 1. It includes some corresponding, effective teaching and learning methods as well as related neurodidactical elements.

This concept built the basis for different projects like "Informatics - A child's play" and the "Informatics-Lab". All workshops, stations and activities considered at least one of the four principles.
TABLE I

Brain-based Teaching concept [4]

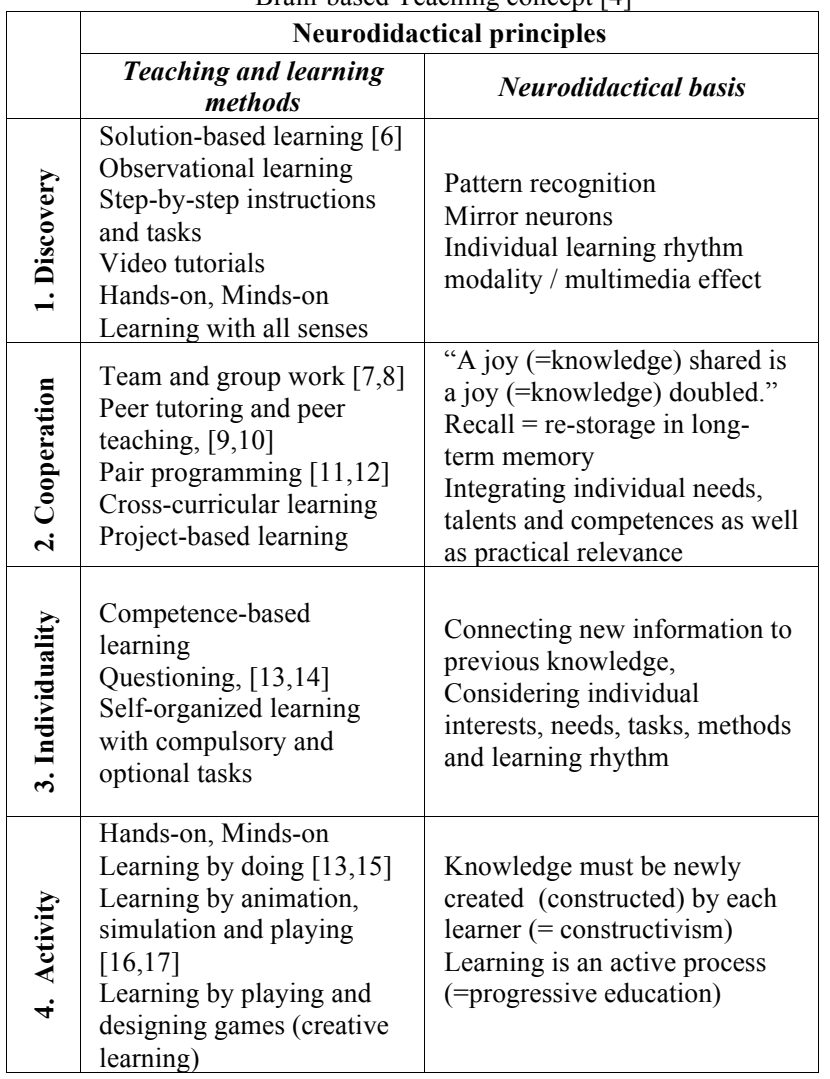

\section{INFORMATICS-LAB}

\section{A. The Lab}

The Informatics-Lab took place in July 2014 as a part of the project "Informatics - A child's play". Its main aim was to teach basic principles of computer science to children between the ages of five and fifteen in a playful and exciting way. For that purpose, a seminar room at the Institute of Informatics Didactics at the "Alpen-Adria University" in Klagenfurt turned into an open lab for four weeks. Children, especially from university staff but also from outside the university, parents and interested teachers were invited to visit the lab and to get in touch with technology and some informatics concepts. Based on projects like "Informatik erLeben" (Experiencing Informatics) [18] or "Computer Science Unplugged" [17] some of these concepts were adapted for different age groups and playfully presented in different stations with or without the direct usage of a computer. Participants were accompanied by trainees aged between 16 and 19, who were employed for an internship at the university and developed further teaching material following the "COOL Informatics" concept. The Informatics-Lab did not include day care, so parents were supposed to take care of their children. If the children were very interested, they had the possibility to visit the lab more than once. They could attend as often as they wanted. 


\section{B. Stations and Workshops}

Most of the stations and materials were new and were developed by members of the Institute of Informatics Didactics. Only the stations $1+1=10$ (binary numbers) and Top secret! (Codification and encryption) based on work of other projects $[17,18]$, but were adapted corresponding to the principles of the COOL Informatics concept. Each station represented one topic of informatics and was comparable to a short workshop. After some time of explanation, the participants could discover different concepts or work on their own on their favorite content. Apart from quizzes, matching exercises and other tasks, the trainees had the idea to create online games for each station concerning the subject matter. They generated QR-codes that were directly linked to the online resources to easily find them. Once a child had fully understood a station, he or she was encouraged to explain its content to peers or expand and improve each station according to his or her own ideas. Afterwards, the children could create their own websites, program games or animation with the block-based programming language Scratch, or make quizzes on respective sites on the Internet. A competition was launched at the end of the project, in which the best two games, websites or other contributions could win certain prices. For children who came regularly, a puzzle hunt through the university was made. At different stations all around the building, the children had to do certain tasks using the knowledge they had acquired in the Informatics-Lab. The following sections explain the activities at each station and demonstrate the link to the "COOL Informatics" concept.

1) All is logic (Boolean Algebra): This station was developed for pupils in order to understand simple sentential logic. Basic concepts of Boolean algebra were hidden in short stories and resulted in a truth table, which could be built with the help of picture cards. An example is that each visitor of a birthday party, shown as smileys, displayed a row in the table. Instead of using variables the visitor should wear a mask AND bring a gift to get a piece of cake. Green and red smileys signified which visitor was masked and which had a present for the birthday child. The same scenario was played through with the OR operator changing the story to visitors could wear a mask or bring a present. In this station all four principles of the "COOL Informatics" concept discovery, cooperation, individuality and activity are included. The participants discovered that logical constructs could be found in different situations of everyday life of each person. With step-by-step instructions they could learn to create a truth table for the sample. The learners could further try to create a truth table on their own or to cooperate in teams or groups of more people. They could individually choose between different stories, which gave the basic information for the truth table. If no given story raised their interest, they were motivated to describe their own situation and to try to include logical statements. At this point, the learners were active and tried to solve problems on their own or even find new problems and stories. They were learning by doing.

2) $1+1=10$ (Binary Numbers): At this station, pupils had the opportunity to understand in detail how a computer is calculating values. A first problem for pupils can be to manage the conversion from decimal to binary numbers and vice versa. With the help of cards with dots on them, which represent the value of each position of the binary number as countable points, the children could easily calculate the correct decimal representation of a binary number. Further summation and subtraction in the binary system was learned. This station can be connected to at least the three principles discovery, cooperation and activity from the "COOL Informatics" concept. With the help of samples, the learners could recognize the pattern of converting and reconverting decimal into binary numbers. They could again work together in groups and help each other if necessary and possible. Of course, the learners had to be active to comprehend the mechanism of this conversion. With the cards with the dots they could work without difficult calculations.

3) Top secret! (Codification and Encryption): At this station, the main principles of codification and encryption in informatics were explained with the help of different examples, like the Morse code and the Caesar Cipher. As a first step, the pupils learned to en- and decode messages with the symbols of the Morse alphabet. They could do this by using the table, which included all characters or with the help of a code-tree. By sending and receiving messages with flashlights the visitors could test their skills. With green and red letter-cards, the basic technique of encryption and decryption was explained to the visitors. Therefore, it was easy to understand how simple algorithms work and the children could write their own secret texts. They further got the task to try to encrypt different text samples on their own. For this purpose, they could use the letter-cards or a Caesar Cipher wheel. At this station again all four principles discovery, cooperation, individuality and activity can be found. To use a code was not new to most of our participants. So they could concentrate on the Morse code as sample and discover its pros and cons. With the help of the letter cards and the Caesar Cipher wheel the participants could easily encrypt messages on their own and discover the process of en- and decryption. They worked in teams and exchanged encoded or encrypted secret messages with their teammates. Furthermore, the teams had the task to individually invent their own code with their own ideas of good usable symbols. At this station, the participants mostly learned the mechanisms by using them and therefore had to be active all the time.

4) Fully Networked (Internet and Networks): The aim of this station was to explain the children what networks are, which components they include, and how data can be sent over very large networks or connected networks like the internet. At first different cards and simple diagrams, which represented the users, routers, servers or data packages, were used to describe the overall functionality of networks. After that every single node of the diagram was explained. To show that in networks errors can occur the visitors played Chinese whispers and they learned an easy algorithm how errors can be detected. Three of the four principles of the "COOL Informatics" concept can be found at this station. These are discovery, cooperation and activity. As a first, the participants 
learned more about the structure of networks by investigating the connected cards and diagrams. After that they discovered each single component of the network on their own. This could happen alone or in groups. Cooperation was also important at playing Chinese whispers to simulate the path of a message from sender to receiver through a network. Most parts of the network should be discovered by the learners on their own, what means they had to be active during this time.

5) Touchable Computer (Computer Systems and Hardware): At this station the pupils learned about how a computer works. Therefore, they were allowed to open a computer and identify the important parts such as mainboard, central processing unit, random access memory, hard disk drive and so on. Furthermore, theoretical concepts such as how the internal parts function were explained to the pupils so that they understand how these components work together in order that a computer works. This station can be connected to the three principles discovery, cooperation and activity. By disassembling the learners discovered the main components of a computer on their own. They had to discuss the functionality of the components in groups and to try to reassemble the computer together. During all the time the participants were active.

6) The Data Bus is on its Way! (Data Bus): Another important point in the Informatics Lab was to explain how computers process data. In order that pupils understood this concept a printed carpet with streets and buildings was used to demonstrate the mainboard and a simple toy bus displayed the data travelling from one part of the mainboard (represented by the carpet) to another. Small houses with labels represented the components of the computer. With the metaphor of the carpet as mainboard and the buildings as computer components the processing of data could be discovered in a very playful way. While the children were driving the toy bus from one house to the other, they were listening to the interns explaining the way of the data and the functioning of the components.. The data bus station, too, includes all four COOL-principles discovery, cooperation, individuality and activity. In a second turn, the participants worked in teams to guide each other through the streets and to find the right path for the data. They could individually choose how fast they followed the path and if they wanted to learn more of each component or not. All members of the teams had to be active and help each other.

7) Well Planned is Half Done (Modelling and Diagrams): In this station, several examples of Entity-Relationship models in Chen-Notation [19] and UML class and activity diagrams were presented to the children so that they understood the first basic principles behind the concept of modeling. One simplified example of an Entity-Relationship-model contains the two entities "author" and "book" with the relation "writes". Each of them has three attributes. The "author" includes "first name", "last name" and "address" and attributes of the "book" are "title", "page number" and "ISBN". With the class diagram the concept of generalization was explained. In one example an "animal" class built the superclass of a "cat" and a "fish" class. The children used these patterns to draw their own very creative diagrams. They used the diagrams to tell stories or to describe activities. An exemplary outcome of this station is shown in section 4.3. All four principles can be found at this working station. The participants could discover different diagrams and models on their own and try to figure out what they were representing. After a short introduction to the topic they could work in groups or for their own and try to tell a story with the help of simplified elements of an ER-diagram. Thereby the principles cooperation and individuality were covered. The principle activity was also included because the participants had to be active to create their own diagrams and to present their stories.

\section{EVALUATION}

\section{A. Methods}

Before starting to discover the stations the visitors had to complete, a short questionnaire about their previous knowledge in, their interest in, and their understanding of informatics. All in all it included thirteen questions concerning informatics, computer or the Internet and was divided into two blocks. In the first block all questions could be answered with "yes" or "no". For the answers in the second block they had to estimate themselves in the context of informatics. They were asked:

1. "Are you interested in informatics and computers?"

2. "Do you think you are well schooled in informatics? Provide an estimate of your abilities."

3. "Could you imagine to choose the subject Informatics in a secondary school or to visit a secondary school with focus on Informatics?"

4. "Could you imagine starting a career in informatics?"

5. "What does informatics mean to you?"

For a pre-post comparison the participants had to fill in a second questionnaire after the workshops, which included three questions (2.-4.) equal to the pre-test. Further they had to

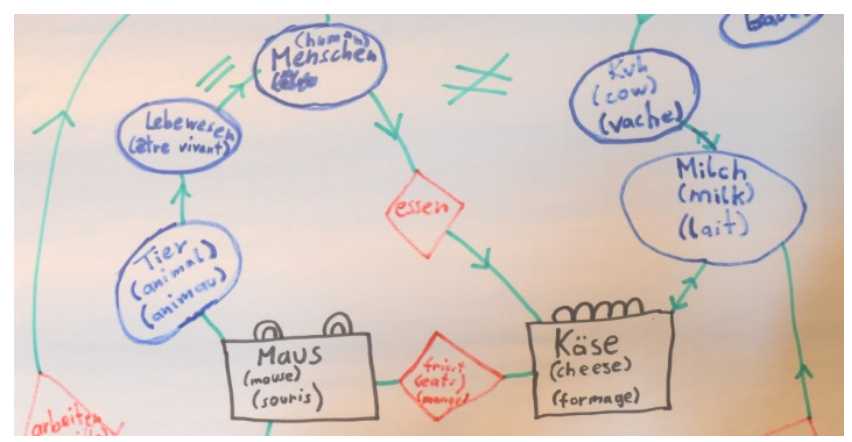

Fig. 1 The diagram with the title "Mouse and Cheese"

grade each workshop separately to find out, which one the children liked the most. To evaluate the Informatics-lab all interns and adult visitors with knowledge in similar fields of activity were expected to contribute to a SWOT analysis and describe strengths, weaknesses, opportunities and threats of this project. The development of new teaching material by

$14^{\text {th }}$ LACCEI International Multi-Conference for Engineering, Education, and Technology: "Engineering Innovations for Global Sustainability”, 20-22 July 2016, San José, Costa Rica. 
interns has been documented, tested and revised. The aim of these developments is to foster the understanding of informatics issues. The next section gives an impression of the outcomes of the Informatics-Lab.

\section{B. Outcomes of Interns: Software - Operating System - Hardware}

The interns developed material for a station that wants to simplify the understanding of the function of an operating system. At this station, the pupils should try to understand how computer hardware, the operating system and the software work together. Therefore, images of a ship, the captain, the crew and the passengers should help them to understand the basic functionalities. For instance, the ship represented the computer hardware, the captain was the operating system and therefore responsible for the main interaction between the hardware and software. The software itself was represented and explained as the crew. Last but not least were the passengers who were explained as the users of the software and that those profited greatly from the smooth interaction between all three components. There was also the idea of a pirate ship that displays an attacker who wants to steal information from the computer. To save the ship from attackers it carried some canons, which should stand for different protection software like a firewall. It can be seen that this metaphor is very fancy and interesting but also contains some issues and should be revised.

\section{Outcomes of Participants / Children: Modeling}

To evaluate if the participation in the Informatics-Lab is able to consolidate the knowledge about informatics, the outputs of the participants has been collected and documented, as the following example will illustrate. During the participation of the station "Well planned is half done" two girls of a lower secondary school decided to draw a diagram to tell a story about a mouse and cheese. They wanted to learn vocabulary in English and French as foreign languages. With the knowledge from the workshop they started to draw an Entity-Relationship model, consisting of a "mouse" and a "cheese" entity. They easily found the relationship "eats" between these two. But they did not stop at this point and invented a diagram that has only a few similarities with an Entity-Relationship model left. Although the diagram was not a completely correct ER-diagram, the girls used different principles of modeling and planning to tell their story and to learn vocabulary with the help of it. Therefore, this was a very interesting example for the outcomes of the Informatics-Lab. A section of the resulting diagram can be seen in Figure 1. Further studies will concentrate on the different errors that children make at their first steps in drawing diagrams. For an evaluation of course the age and the psychological development of the students have to be considered. But this would exceed this paper and will be discussed in a future work.

\section{Empirical Results}

In the four weeks the Informatics-Lab had all together 76 visitors of whom 34 were male and 42 female. 57 visitors were between 5 and 17 years old. The main target group was represented by children from 5 to 12 years ( 24 boys and 28 girls). After the workshops 50 of the participants were asked some questions for the pre-post comparison and their own evaluation of the workshops. The first five questions could be answered with "yes", "maybe" or "no". At the question if they liked the lab $72 \%$ chose with the answer "yes", 8 \% "maybe", no one was answered with "no", but $20 \%$ did not give an answer. When they were asked if the content was easy to understand, $42 \%$ believed it was easy, $30 \%$ were not that sure, $10 \%$ thought that some parts were not that easy to understand and $18 \%$ gave no answer. Following their own estimation, $46 \%$ were more interested in informatics after the workshops than before, $32 \%$ were not sure, $4 \%$ did not think they were more interested and $18 \%$ did not answer this question. The increased interest could also be seen in the answers to the question if they wanted to attend more informatics-workshops: $52 \%$ answered with "yes", $20 \%$ with "maybe", only $8 \%$ with "no" and $20 \%$ gave no answer. A surprising result provided the question if the participants thought that their attitude towards informatics had changed in a positive way after they visited the lab. $38 \%$ meant "yes", 26 $\%$ said "maybe", only $6 \%$ were sure that their attitude did not change a bit and $30 \%$ did not answer. Also, the grading for each station delivered an interesting result. The participants could choose numbers between 1 and 5 for each workshop. According to the Austrian grading-system 1 meant "very good" and 5 "insufficient". In Figure 2 the percentage of the grades for all workshops can be seen. The station "The Data bus is on its way!" was graded with the best mark 1 by $86 \%$ and hence was the most popular workshop of the InformaticsLab. It was followed by "Top secret!" with $81 \%$ and "All is logic" with $74 \%$ of the grade 1 . One reasons for this ranking may be that the best three stations were easier to understand for younger children because of the content itself or the closer connection to their daily life (toy bus, birthday party).

The pre-post comparison also shows some interesting aspects. It contains the three question blocks "Knowledge in Informatics", "Focus on Informatics" and "Career in Informatics". These are the shortcuts for the questions 2.-4. from Section 4.2 of this paper. The answers of the participants

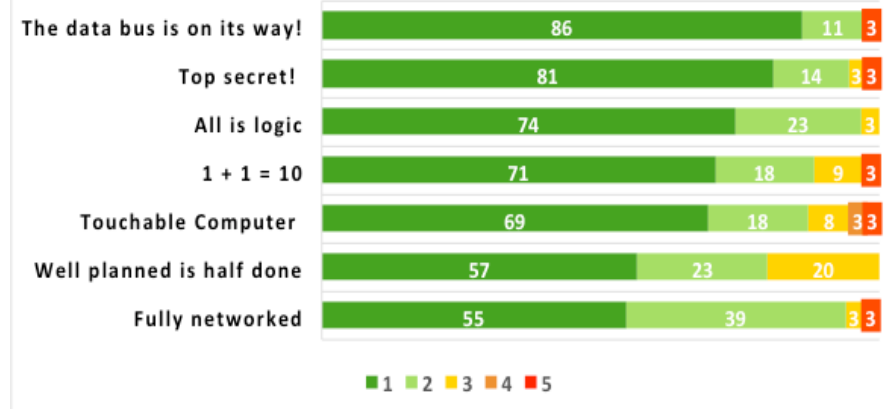

Fig. 2 Evaluation of the stations by the visitors ( $\mathrm{n}=50,1$ meant "very good" and 5 "insufficient")

before and after the workshops were compared for each block and the results can be seen in Figure 3. In the block "Knowledge in Informatics" it is visible, that the numbers of the answers "no" decreased from $25 \%$ before the workshops 
to $6.3 \%$ after the workshops and of "rather no" from $33.3 \%$ to $15.6 \%$. In contrast the numbers of the answers "rather yes" and "yes" increased from $30.6 \%$ to $46.9 \%$ and from $11.1 \%$ to $31.3 \%$. That shows a great difference between the conditions and knowledge before and after a visit at the Informatics-Lab. In the block "Focus on Informatics" the difference is also visible but in a smaller dimension. Before the workshops $15.8 \%$ of the visitors could not and $18.4 \%$ could "rather not" imagine to choose the subject Informatics in a secondary school or to visit a secondary school with focus on informatics. After their participation the value of the answer "no" decreased to $3.1 \%$ and of "rather no" increased to $21.9 \%$. Anyway, the summed number of negative answers shrank and the sum of positive answers grew. Although before the workshops $13.2 \%$ said "rather yes" and after the workshops the number decreased to $12.5 \%$. But the percentage of the answer "yes" increased from 18.4 to $31.3 \%$. Hence, the interest in informatics and the desire to learn more about it increased. The last block "Career in Informatics" shows that after the workshops more participants could imagine to start a career in a field of Informatics. Although the sum of negative answers increased, the sum of positive answers increased much more and only the "don't know" answers decreased. It can be seen that from the $25.6 \%$ of the participants who did not know, if they could imagine to start a career in the fields of informatics before the workshops, only $12.9 \%$ were left after their attendance at the Informatics-lab. After the workshops the number of positive answers, including "rather yes" and "yes" answers, additionally increased from $38.5 \%$ to $48.4 \%$.

It has to be mentioned that there are some aspects that threaten the validity of this study. The graduation of the working stations is, of course, not significant, because each intern explained the topics in a different way. For example, a student of a technical school uses more technical terms to describe concepts, which may be hard to understand for children. Further each station used different methods and materials to transmit the content and each of them addresses various interests.

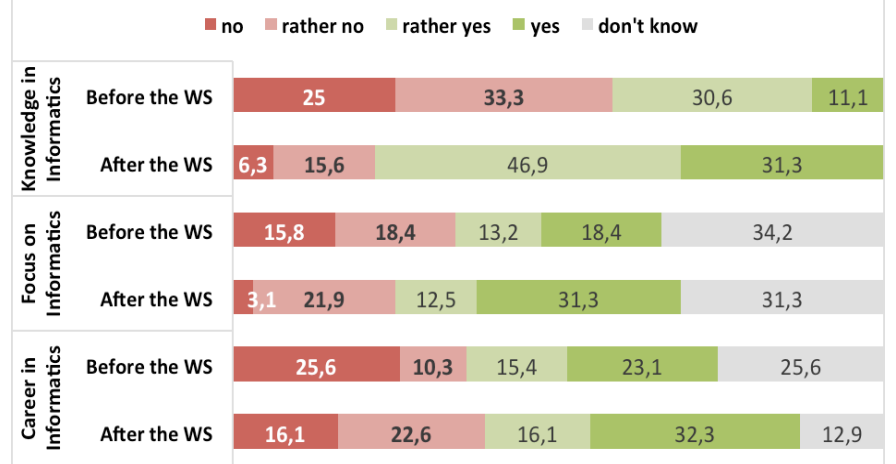

Fig. 3 Pre-post comparison of the three blocks $(n=50)$

\section{CONCLUSION AND FUTURE WORK}

In July 2014 the Informatics-Lab took place for the first time. It was a part of the project "Informatics - A child's play" with the aim to bring children of different ages in touch with concepts of informatics. With seven stations, the lab provided a wide range of interesting ideas and topics for all participants of the three target groups, children, trainees and teachers, who had the possibility to be part of the lab during the four weeks. The children could discover and learn new content with the help of the seven trainees. During their preparation time, the trainees had to introduce themselves in several concepts and they could acquire some knowledge on their own. They also benefited from learning by teaching the other visitors. Following the results of the evaluation the main goals of this project could be reached. It has to be said that our target group was relatively small, but the positive results correspond to those of other similar studies [18]. The interest of our visitors in informatics as well as their knowledge of various computer science concepts could be increased. The other main aim of the lab was to prove if the developed teaching units and materials could improve the understanding of informatics concepts and if it is possible to integrate them in other subjects. All in all the Informatics-lab seems to be a useful initiative and a good way to make computer science more popular and interesting. That is why we repeated the Informatics-lab in summer 2015 in an extended version including more stations and more rooms with different topics. During this second summer 312 registered visitors could be recorded, which is a large increase of participants and will be discussed in a follow-up study.

\section{REFERENCES}

[1] Joint Informatics Europe \& ACM Europe Working Group on Informatics Education. 2013. Informatics Education: Europe cannot afford to miss the boat: Report of the joint Informatics Europe \& ACM Europe Working Group on Informatics Education.

[2] J. M. Wing, "Computational Thinking," Communications of the ACM, vol. 49, no. 3, pp. 33-35, 2006.

[3] B. Sabitzer, S. Pasterk, and E. Reci, "Informatics - A Childs Play?!," Proceedings of the International Conference on Education and New Learning Technologies, EDULEARN. StudienVerlag, pp. 1081-1090, 2014.

[4] B. Sabitzer, A Neurodidactical Approach to Cooperative and Crosscurricular Open Learning: COOL Informatics, Habilitation thesis, AlpenAdria-Universität Klagenfurt, 2014.

[5] R. Hölbling, H. Wittwer, and G. Neuhauser, „COOL Cooperatives Offenes Lernen. Impulszentrum für Cooperatives Offenes Lernen,” 2011, http://www.cooltrainers.at/fileadmin/impulszentrum/pdf/Cool_Booklet_1 20x180_lay1.pdf.

[6] A. Renkl, and R.K. Atkinson, "Learning from examples: Fostering selfexplanations in computer-based learning environments," Interactive learning environments, 10(2), 105-119, 2002.

[7] C.J. Roseth, D.W. Johnson, and R.T. Johnson, "Promoting early adolescents' achievement and peer relationships: The effects of cooperative, competitive, and individualistic goal structures," Psychological bulletin, 134(2), 223, 2008.

[8] B. Gokkurt, S. Dundar, Y. Soylu, and L. Akgun, ,The Effects of Learning Together Technique Which is based on Cooperative Learning on Students' Achievement in Mathematics Class," Procedia-Social and Behavioral Sciences, 46, 3431-3434, 2012.

[9] V. Miller, E. Oldfield, and M. Bulmer, "Peer Assisted Study Sessions (PASS) in first year chemistry and statistics courses: insights and evaluations," Proceedings of The Australian Conference on Science and Mathematics Education (formerly UniServe Science Conference) (Vol. 10), 2012.

[10]L. Porter, C. Bailey Lee, and B. Simon, "Halving fail rates using peer instruction: a study of four computer science courses," Proceeding of the

$14^{\text {th }}$ LACCEI International Multi-Conference for Engineering, Education, and Technology: "Engineering Innovations for Global Sustainability”, 20-22 July 2016, San José, Costa Rica. 
44th ACM technical symposium on Computer science education (pp. 177182). ACM, 2013.

[11]N. Salleh, E. Mendes, and J. Grundy, "Empirical studies of pair programming for $\mathrm{CS} / \mathrm{SE}$ teaching in higher education: A systematic literature review," Software Engineering, IEEE Transactions on, 37(4), 509-525, 2011.

[12]C.M. Lewis, "Is pair programming more effective than other forms of collaboration for young students?," Computer Science Education, 21(2), 105-134, 2011.

[13]J. Hattie, Visible Learning: A Synthesis of Over 800 Meta-Analyses Relating to Achievement, Taylor \& Francis, London, New York, 2009.

[14]S.D. Craig, J. Sullins, A. Witherspoon, and B. Gholson, "The deep-levelreasoning-question effect: The role of dialogue and deep-level-reasoning questions during vicarious learning." Cognition and Instruction, 24(4), 565-591, 2006.
[15]H.W. Reese, "The Learning-by-Doing Principle," BEHAVIORAL DEVELOPMENT BULLETIN, 11, 2011.

[16]A. Bollin, E. Hochmüller, R. Mittermeir, and L. Samuelis, „Experiences with Integrating Simulation into a Software Engineering Curriculum," D. Chen, M. Baker, L. Huang (Ed.): Proceedings of 25th IEEE Conference on Software Engineering Education and Training CSEE\&T 2012, 17-19 April 2012, Nanjing, Jiangsu, China. Los Alamitos (CA): IEEE Computer Society Press, pp. 62-75, 2012.

[17]T. Bell, L. Lambert, and D. Marghitu, "CS unplugged, outreach and CS kinesthetic activities," Proceedings of the 43rd ACM technical symposium on Computer Science Education (p. 676). ACM Digital Library, 2012.

[18]R.T. Mittermeir, E. Bischof, and K. Hodnigg, "Showing core-concepts of informatics to kids and their teachers," Teaching Fundamentals Concepts of Informatics. Springer Berlin Heidelberg, 143-154, 2010.

[19]P.P. Chen, "The Entity-Relationship Model--Toward a Unified View of Data," ACM Transactions on Database Systems, Vol 1, 1976.

14 ${ }^{\text {th }}$ LACCEI International Multi-Conference for Engineering, Education, and Technology: "Engineering Innovations for 